\title{
Socio-Demographic and Behavioral Factors for Serious Injury among Adolescents in Malaysia
}

\author{
Mohd Hazrin Hasim¹, Siti Fatimah'1, Nur Shahida', Muhammad Hatta', Mohd Naim¹, \\ Tee Guat Hiong1, R. Rosnah ${ }^{2}$ \\ ${ }^{1}$ Institute for Public Health, Ministry of Health Malaysia, Kuala Lumpur, Malaysia \\ ${ }^{2}$ Disease Control Division, Ministry of Health Malaysia, Kuala Lumpur, Malaysia \\ Email: hazrin@moh.gov.my
}

Received 14 September 2015; accepted 12 December 2015; published 15 December 2015

Copyright (C) 2015 by authors and Scientific Research Publishing Inc.

This work is licensed under the Creative Commons Attribution International License (CC BY). http://creativecommons.org/licenses/by/4.0/

(c) (i) Open Access

\section{Abstract}

This study was to determine the prevalence and socio-demographic associated factors for serious injury among adolescents in Malaysia. The study used data from the Malaysian Global School- based Health Survey which was conducted in 2012. Logistic regression analysis was used to establish associations. Of the 25,507 respondents, $34.9 \%$ (42.1\% males and $27.8 \%$ females) reported having been in a serious injury. Compared to participants who were not bullied, those who reported being bullied were more likely to have sustained serious injury (aOR $=2.2 ; 95 \% \mathrm{CI}[1.95-2.48])$. Adolescents who were involved in physical fighting were $57.5 \%$ (aOR $=2.75 ; 95 \% \mathrm{CI}[2.53-2.99])$ and more likely to have sustained serious injury compared to those who were not involved in the fighting. Meanwhile, adolescents who used substances were $52.3 \%(\mathrm{aOR}=1.68$ [1.52 - 1.85]) and more likely to have sustained serious injury compared to those who did not use substances. Serious injury is frequent among adolescents in Malaysia. Based on studies by Harel, suggestion where reduction of substance use and bullying may be assessed if they have an impact in reducing serious injury among adolescents. Furthermore, educational programmes that focus on the underlying causes and determinants of injury provide an effective and efficient method of injury prevention.

\section{Keywords}

Malaysia, Adolescent, Injury, School Health, Adolescents

\section{Introduction}

Injuries kill more than five million people worldwide annually and cause harm to millions more [1]. They ac-

How to cite this paper: Hasim, M.H., Fatimah, S., Shahida, N., Hatta, M., Naim, M., Hiong, T.G. and Rosnah, R. (2015) Socio-Demographic and Behavioral Factors for Serious Injury among Adolescents in Malaysia. Health, 7, 1651-1656. 
count for $9 \%$ of global mortality, and are a threat to health in every country of the world. Intentional injuries which include self-inflicted injuries account for an increasing share of the injury disease burden, especially among economically productive young adults. A large proportion of people surviving their injuries incur temporary or permanent disabilities [2].

Several studies had focused on the typology of injuries and their socio-economic status correlates [3] [4] particular types of injuries, such as sport injuries [5], the association between family stress and injuries [6], risk behaviors and injuries [7], violence and injuries [4] [8], and other psychosocial determinants [4] [9] [10]. Despite the enormous public health burden imposed by child and adolescent injury, several studies had shown that $71 \%$ 95\% of injuries could be prevented by simple and reasonable means [11] [12]. In developed countries such as Australia, Sweden, Britain, and Canada, injury rates has been reduced by up to $50 \%$ over the past three decades using multi sectored approaches to prevent [13]. In developing countries, studies have been largely limited to hospital-based information which provides information on severe injuries [14] [15].

We prepared an analysis of the 2012 Malaysia Global School-Based Health Survey (GSHS) to estimate the 12 months prevalence of the outcome in request to contribute to the literature on serious injuries. Assessed to the association between a list of predictor variables and self-reported history of injury among in-school adolescents also have been done.

There is no or limited data regarding injury and its social-demographic correlates among adolescents in Malaysia. Therefore, this study aimed to determine the prevalence and social-demographic correlates of serious injury among adolescents in Malaysia.

\section{Material and Method}

\subsection{Study Design}

This study involved secondary analysis of data from the Malaysia Global School-based Student Health Survey (GSHS) conducted in 2012. The GSHS was developed by the World Health Organization (WHO) in collaboration with UNICEF, UNESCO, and UNAIDS with technical assistance from the Centers for Diseases Control and Prevention (CDC), Atlanta, Georgia, United States. The main purpose of the GSHS is to provide data on health and social behaviours primarily among in school adolescents aged 11 - 18 years. A two-stage cluster sample design was used for data representatives of students in the country. At the first stage, schools were selected with a probability proportional enrolment size. At the second stage, classes were randomly selected and all students in selected classes were eligible to participate. The overall response rate was $88.8 \%$. A total of 25,507 students participated in the 2012 Malaysia GSHS.

The following question was asked in order to gather data on the type and cause of injury: During the past 12 months, what was the most serious injury that happened to you? Eight options were provided, ranging from 0 12 or more times. A zero response was described as not having sustained a serious injury, whiles a response of one or more times was classified as having experienced a serious injury. In order to assess history of victimization from bullying the question that was asked was: During the past 30 days, on how many days were you bullied? The responses range from 0 days or any number of days. In terms of involvement in a physical fight, students were asked the question: During the past 12 months, how many times were you in a physical fight? Options include 0 times, one up to 12 or more times. A definition for a serious injury was described as "An injury is serious when it makes you miss at least one full day of usual activities (such as school, sports or job) or requires treatment by a doctor or nurse.”

Other questions in this analysis included substance use: smoking cigarettes or alcohol drinking or drugs. Smoking cigarettes: "During the past 30 days, on how many days did you smoke cigarettes (Coded $1=1$ or 2 to all 30 days, and $0=0$ days)? Alcohol drinking: During your life, how many times did you drink so much alcohol that you were really drunk (Coded $1=1$ or 2 to 10 more times, and $0=0$ times)? Drugs: During your life, how many times have you used drugs (Coded $1=1$ or 2 to 10 times or more times, and $0=0$ times)?”

\subsection{Ethical Considerations}

Permission to carry out the study through ethical approvals was obtained from the Ministries of Health Research and Ethic Committee and Ministry of Education Ethics Committee. Informed consent to participate in the study was collected to all students from selected classes. Confidentiality was upheld by allowing for anonymity in 
completing the questionnaire.

\subsection{Data Analysis}

Data was analysed using SPSS software version 19.0. Unweighted frequencies and their weighted percentages are reported. Reclassification was done for the main outcome (most serious injury) in two categories: 1 for "I was not seriously injured during the past 12 months", and 2 for other responses. We conducted bivariate and multivariate logistic regression analyses in order to estimate associations between independent factors and the outcome variable. The hypotheses were "There were no significant associations between socio-demographic factors and serious injury”. Associations between potential risk factors and injuries among adolescents were evaluated calculating odd ratios (OR). We reported prevalence of serious injury as well as the unadjusted odd ratios (OR) and adjusted odds ratios (aOR) together their 95\% confidence intervals (CI).

The weighting used to estimate prevalence was calculated using the formula: $\mathrm{W}=\mathrm{W} 1 * \mathrm{~W} 2 * \mathrm{f} 1 * \mathrm{f} 2 * \mathrm{f} 3 * \mathrm{f} 4$, where W1 is the inverse of the probability of selecting the school. W2 is the inverse of the probability of selecting the classroom within the school. $\mathrm{f1}$ is a school-level non-response adjustment factor calculated by school size category (small, medium, large). f2 is a class-level non-response adjustment factor calculated for each school. $\mathrm{f} 3$ is a student-level non-response adjustment factor calculated by class and $\mathrm{f} 4$ is a post stratification adjustment factor calculated by grade.

\section{Results}

\subsection{Characteristics of the Study Sample}

Table 1 shows a total of 25,507 students participated in the study of which mainly attending Form 1 to Form 5. Most of the sample were male (50.2\%), 38.0\% were 16 years and above, and most (21.0\%) were in Form 1.

\subsection{Injury Characteristics}

Of the 25,507 students, $34.9 \%$ (42.1\% among boys and 27.8\% among girls) had sustained at least one serious injury in past 12 months. The most frequently identified cause of injury was fall (36.7\%), followed by "something else" (26.6\%), and motor vehicle accident (20.0\%). The most sustained injury involved cut, puncture, or stab wound (6.2\%), followed by broken bone or dislocated joint (4.2\%) and concussion or other head or neck injury (2.5\%). The most frequent serious injuries among males were cut, puncture, or stab wound (7.8\%) and broken bone or dislocated joint (6.3\%). Concussion or other head or neck injury (2.6\%) was the most frequent serious injury reported by females (Table 2).

Table 1. Socio-demographic characteristics.

\begin{tabular}{|c|c|c|}
\hline Type of serious injury & $\mathrm{n}^{1}$ & $\%^{2}\left(95 \% \mathrm{CI}^{3}\right)$ \\
\hline \multicolumn{3}{|l|}{ Age (years) } \\
\hline$<14$ & 5395 & $21.2(19.5$ - 23.0) \\
\hline 14 & 5357 & $20.6(18.3-23.0)$ \\
\hline 15 & 5554 & $20.2(18.6$ - 21.9) \\
\hline $16+$ & 9187 & $38.0(36.6$ - 39.5) \\
\hline \multicolumn{3}{|l|}{ Sex } \\
\hline Male & 12732 & $50.2(48.3-52.0)$ \\
\hline Female & 12729 & $49.8(48.0$ - 51.7) \\
\hline \multicolumn{3}{|l|}{ School grade } \\
\hline Remove class & 162 & $0.8(0.4-1.5)$ \\
\hline Form 1 (13 years old) & 5271 & $21.0(19.0-23.2)$ \\
\hline Form 2 (14 years old) & 5329 & $20.4(17.9-23.2)$ \\
\hline Form 3 (15 years old) & 5599 & $20.1(18.2-22.1)$ \\
\hline Form 4 (16 years old) & 4515 & $19.2(16.9-21.8)$ \\
\hline Form 5 (17 years old) & 4571 & $18.4(16.3-20.7)$ \\
\hline
\end{tabular}

${ }^{1}$ unweighted frequency; ${ }^{2}$ weighted percent; ${ }^{3}$ confidence interval. 
Table 2. Frequency of the most serious injury among adolescents.

\begin{tabular}{cccc}
\hline & Total & Males & Females \\
$\%(95 \% \mathrm{CI})$
\end{tabular}

${ }^{1}$ weighted percent; ${ }^{2}$ confidence interval.

Table 3 shows the factors associated with serious injury. All the factors considered in the study were significantly associated with serious injury in both analyses (bi-variate and multivariate) except age. Compared to females, males more likely to have sustained serious injury (aOR $=1.47$, 95\% CI [1.35 - 1.59]). Adolescents who were bullied were $52.3 \%$ (aOR $=2.2$; 95\% CI [1.95 - 2.48]) more likely to have sustained serious injury compared to those were not bullied. Compared to participants who were not engaged in physical fighting, 57.5\% $(\mathrm{aOR}=2.75[2.53-2.99])$ those who engaged in physical fighting more likely to have sustained serious injury. Meanwhile, adolescents who used substances were $52.3 \%(\mathrm{aOR}=1.68$ [1.52 - 1.85]) more likely to have sustained serious injury compared to those who did not use substances.

\section{Discussions}

Malaysia GSHS of school going adolescents showed that overall prevalence of having serious injury during the past 12 months was $34.9 \%$. This prevalence was lower than Djibouti GSHS 2007 which is $61.1 \%$ of participant, (63.2\% male, $57.8 \%$ female) Botswana GSHS 2005 which is $65.8 \%$ of respondents ( $68.1 \%$ among boys, $63.8 \%$ among girls) [16] [17]. Our prevalence was also lower compared to Indonesia (45.9\%), Sri Lanka (37.2\%) and Thailand (46.8\%), but higher compared to Myanmar (27.0\%).

Male students $(42.1 \%)$ were significantly more often to have serious injury compared to female students (27.8\%) and it was similar with findings in some other studies. The prevalence estimate obtained from this study is similar to a study reported by Muula et al. [16]. In the Bostwana study, although males were also more likely to having sustained serious injury than females, the gender gap was smaller (68.1\% and 63.8\% among boys and girls respectively) [17]. The study found that the most common serious injury among males were cut, puncture, or stab wound was similar with Muula et al. study in Djibouti. The most common serious injury among females was similar with males meanwhile different than Muula et al. study where the most common were broken bone or dislocated joint.

The findings of our study was similar with the study done in Botswana, where age was not significantly associated with serious injury, while other studies by Yang, Yeh and Lin among adolescents Taiwan [18] have found such differences. In our study, adolescent who had been bullied, had involved in physical fighting and substance 
Table 3. Prevalence and factors associated with most serious injury.

\begin{tabular}{|c|c|c|c|c|c|}
\hline Factor & $\begin{array}{c}\text { Count } \\
\mathrm{n}\end{array}$ & $\begin{array}{c}\text { Estimated } \\
\text { population, } \mathrm{N}\end{array}$ & $\begin{array}{l}\text { Injury prevalence } \\
(95 \% \mathrm{CI})\end{array}$ & $\mathrm{OR}^{1}\left(95 \% \mathrm{CI}^{2}\right)$ & $\mathrm{aOR}^{3}\left(95 \% \mathrm{CI}^{2}\right)$ \\
\hline \multicolumn{6}{|c|}{ Age (years) } \\
\hline$<14$ & 1669 & 147,378 & $36.4(34.0$ - 38.9) & $1.16(1.01-1.32)$ & $0.98(0.86-1.12)$ \\
\hline 14 & 1691 & 143,939 & $36.6(34.3-39.0)$ & $1.17(1.04-1.31)$ & $1.01(0.91-1.11)$ \\
\hline 15 & 1576 & 134,388 & $35.0(32.1-38.0)$ & $1.09(0.94-1.26)$ & $1.05(0.92-1.19)$ \\
\hline $16+$ & 2501 & 238,252 & $33.1(31.3-35.0)$ & 1 & 1 \\
\hline \multicolumn{6}{|l|}{ Sex } \\
\hline Male & 4450 & 395,958 & 42.1 & $1.89(1.76-2.03)$ & $1.47(1.35-1.59)$ \\
\hline Female & 2975 & 266,822 & 27.8 & 1 & 1 \\
\hline \multicolumn{6}{|l|}{ Bullied } \\
\hline Yes & 1894 & 171,587 & 52.3 & $2.95(2.61-3.34)$ & $2.2(1.95-2.48)$ \\
\hline No & 4916 & 436,138 & 29.3 & 1 & 1 \\
\hline \multicolumn{6}{|c|}{ Involved in physical fighting } \\
\hline Yes & 3228 & 293,837 & 57.5 & $3.72(3.44-4.02)$ & $2.75(2.53-2.99)$ \\
\hline No & 4210 & 370,531 & 26.7 & 1 & 1 \\
\hline \multicolumn{6}{|c|}{$\begin{array}{l}\text { Substance use (Alcohol, or smoking, } \\
\text { or drug use for the past } 30 \text { days) }\end{array}$} \\
\hline Yes & 1824 & 176,521 & $52.3(50.0$ - 54.6) & $2.47(2.27-2.70)$ & $1.68(1.52-1.85)$ \\
\hline No & 5495 & 451,892 & $30.8(29.5$ - 32.1) & 1 & 1 \\
\hline
\end{tabular}

$\mathrm{OR}^{1}$ : unadjusted odds ratio; $\mathrm{CI}^{2}$ : confidence interval; $\mathrm{aOR}^{3}$ : Adjusted odds ratio.

users (smoking, drinking or drugs) were more likely to report serious injury compared to those with no such experiences. These findings were similar with Peltzer [19] study where being bullied, drunkenness were found to be predictors for injuries while Starkuviene and Zaborkis [19] study, found that being bullied, poor self-assessed health and unhappiness were associated with serious injury among Lithuanian school adolescents. Associations between the number of multiple risk behaviours with serious injury also reported among Scottish school adolescents by Picket study [10].

Our study has several limitations. Firstly, eligible study participants were only those adolescents who were enrolled in schools. Our findings may therefore not be applicable to out of school adolescents in Malaysia. Secondly, only students who were present in school on the day the survey was administered at a particular school were surveyed. No effort was made to follow-up on absent students. To the extent that out of school adolescents may be different in their behaviours and experiences, our findings may not be applicable to them. Furthermore, due to the cross sectional nature of the survey, it is not possible to assign causation to the factors that are associated with physical fighting.

In 2010, the Director General of Education under the Ministry of Education, Malaysia has issued guidelines on preventing and dealing with acts of bullying among students. The steps to be taken by the school are to provide a safety complaint pupil, establish disciplinary committees of schools and hostels [20].

\section{Conclusion}

We have estimated the prevalence of serious injury among adolescents in Malaysia. There is a need to explore the effectiveness of school-based intervention programs for injury prevention. Educational programmes which focus on the underlying causes and determinants of behaviour rather than individual behaviours themselves may therefore provide an effective and efficient method of organising health education for adolescents.

\section{Acknowledgements}

The authors wish to thank the Director General of Health Malaysia for his permission to publish this paper. The authors would like to record their sincere appreciation to the Terengganu and Johor, and their staff the support in data collection. 


\section{References}

[1] Peden, M., Oyegbite, K., Ozanne-Smith, J., et al. (2008) World Report on Child Injury Prevention. Tech. Rep., Unicef and WHO.

[2] Lopez, A.D. and Mathers, C.D. (2006) Measuring the Global Burden of Disease and Epidemiological Transitions: 2002-2030. Annals of Tropical Medicine and Parasitology, 100, 481-499. http://dx.doi.org/10.1179/136485906X97417

[3] Molcho, M., Harel, Y., Pickett, W., Scheidt, P.C., Mazur, J. and Overpeck, M.D. (2006) The Epidemiology of Non-Fatal Injuries among 11-, 13- and 15-Year Old Youth in 11 Countries: Findings from the 1998 WHO-HBSC Cross National Survey. International Journal of Injury Control and Safety Promotion, 13, 205-211. http://dx.doi.org/10.1080/17457300600864421

[4] Pickett, W., Molcho, M., Simpson, K., et al. (2005) Cross National Study of Injury and Social Determinants in Adolescents. Injury Prevention, 11, 213-218. http://dx.doi.org/10.1136/ip.2004.007021

[5] MacKay, M., Scanlan, A., Olsen, L., et al. (2004) Looking for the Evidence: A Systematic Review of Prevention Strategies Addressing Sport and Recreational Injury among Children and Youth. Journal of Science and Medicine in Sport, 7, 58-73. http://dx.doi.org/10.1016/S1440-2440(04)80045-8

[6] Scott, H. (2009) Family Matters: An Examination of the Association between Family Structure and Youth Injury. PhD thesis, University of Toronto, Toronto, Canada.

[7] Pickett, W., Schmid, H., Boyce, W.F., et al. (2002) Multiple Risk Behavior and Injury: An International Analysis of Young People. Archives of Pediatrics and Adolescent Medicine, 156, 786-793. http://dx.doi.org/10.1001/archpedi.156.8.786

[8] Harel, Y. (1998) Injuries and Youth Violence. WHO: Health Behavior in School-Aged Children: Research Protocol for the 1997-1998 Survey.

[9] Currie, C.E., Williams, J.M., Wright, P., Beattie, T. and Harel, Y. (1996) Incidence and Distribution of Injury among Schoolchildren Aged 11-15. Injury Prevention, 2, 21-25. http://dx.doi.org/10.1136/ip.2.1.21

[10] Scheidt, P.C., Harel, Y., Trumble, A.C., Jones, D.H., Overpeck, M.D. and Bijur, P.E. (1995) The Epidemiology of Nonfatal Injuries among US Children and Youth. American Journal of Public Health, 85, 932-938. http://dx.doi.org/10.2105/AJPH.85.7.932

[11] Bergman, B. and Rivara, F.P. (1991) Sweden’s Experience in Reducing Childhood Injuries. Pediatrics, 88, 69-74.

[12] Onwuachi-Saunders, S., Forjuoh, N., West, P. and Brooks, C. (1999) Child Death Reviews: A Gold Mine for Injury Prevention and Control. Injury Prevention, 5, 276-279. http://dx.doi.org/10.1136/ip.5.4.276

[13] Hyder, A.A., Peden, M. and Krug, E. (2009) Child Health Must Include Injury Prevention. The Lancet, 373, $102-103$. http://dx.doi.org/10.1016/S0140-6736(08)61736-5

[14] Bartlett, S.N. (2002) The Problem of Children's Injuries in Low-Income Countries: A Review. Health Policy and Planning, 17, 1-13. http://dx.doi.org/10.1093/heapol/17.1.1

[15] Razzak, J.A., Luby, S.P., Laflamme, L. and Chotani, H. (2004) Injuries among Children in Karachi, Pakistan-What, Where and How. Public Health, 118, 114-120. http://dx.doi.org/10.1016/S0033-3506(03)00147-1

[16] Muula, A.S., Siziya, S. and Rudatsikira, E. (2007) Prevalence and Socio-Demographic Correlates for Serious Injury among Adolescents Participating in the Djibouti 2007 Global School-Based Health Survey. BMC Research Notes, 4, 372. http://dx.doi.org/10.1186/1756-0500-4-372

[17] Yang, C.Y., Yeh, Y.C., Cheng, M.F. and Lin, M.C. (208) The Incidence of School-Related Injuries among Adolescents Aged 11-15. British Journal of Sport Medicine, 32, 291-296.

[18] Peltzer, K. and Pengpid, S. (2013) Injury and Social Correlates among In-School Adolescents in Four Southeast Asian Countries. International Journal of Environmental Research and Public Health, 9, 2851-2862. http://dx.doi.org/10.3390/ijerph9082851

[19] Starkuniviene, S. and Zaborski, A. (2008) Links between Accidents and Lifestyle Factors among Lithuanian School Children. Medicine (Kaunas), 41, 73-80.

[20] Ministry of Education (2010) Surat Pekeliling Ikhtisas Bil.8/2010 Garis Panduan Mencegah dan Menangani Perbuatan Buli Dalam Kalangan Murid di Sekolah. http://www.moe.gov.my/v/pekeliling-ikhtisas-view?id=649 